( ) Journal of Innovation and Entrepreneurship

a SpringerOpen Journal

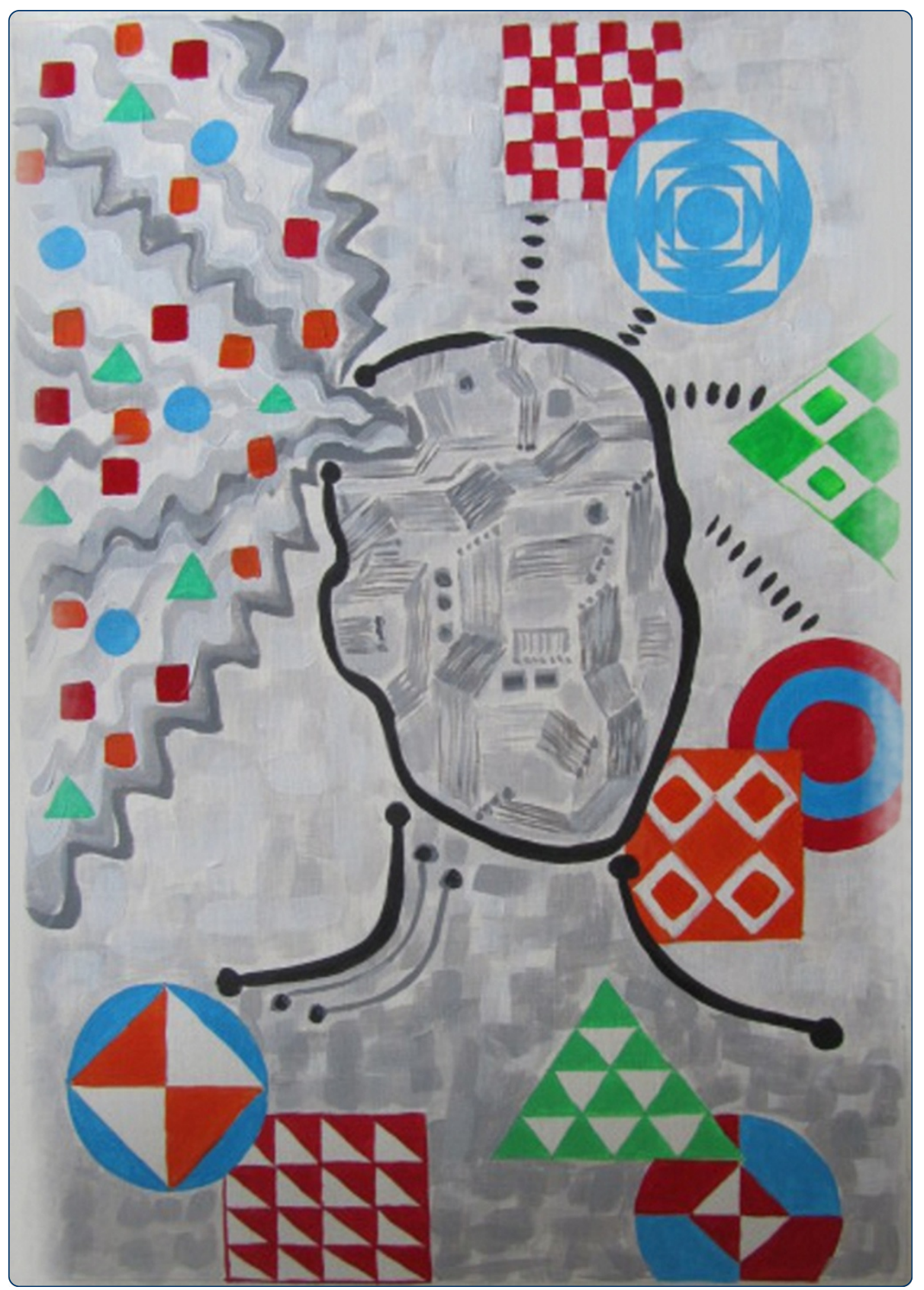

\title{
Women entrepreneurs: 'we cannot have change unless we have men in the room'
}

Kamberidou

咱 Springer 


\section{Women entrepreneurs: 'we cannot have change unless we have men in the room'}

Irene Kamberidou, ${ }^{1,2}$

\author{
Correspondence: \\ irene.kamberidou@ \\ womenandtechnology.eu \\ ${ }^{1}$ Executive Group of the European \\ Centre for Women and Technology \\ (ECWT), Grønland 58, N-3045, \\ Drammen, Norway \\ ${ }^{2}$ Faculty of Sport Science, University \\ of Athens, Ethnikis Antistasis 41, \\ Dafne 17237, Greece
}

\begin{abstract}
What is being done to support female entrepreneurship and in particular promote the ways in which information and communication technologies (ICTs) can encourage and facilitate it? Is today's business climate more inviting to women entrepreneurs? Are women equipped to thrive in this digital age? Current, future, and aspiring women entrepreneurs responded to these questions, and many more, at the recent European conference in Athens, Greece 'More Technologies? More Women entrepreneurs!' at which Madi Sharma, member of the European Economic and Social Committee argued that 'we cannot have change unless we have men in the room.' The European conference showed women - and men - the advantages and opportunities that ICTs can offer them for the development of their business initiatives. It also presented 12 European projects that focus on women's entrepreneurship and how ICT facilitates and fosters it. The European Commission is dynamically promoting, supporting, and encouraging female entrepreneurship. Europe needs more women entrepreneurs and actions are being taken to overcome the obstacles and change mindsets. This paper examines discussions and research on female entrepreneurial activity and provides Tips from successful women entrepreneurs who tell how they have been using new technologies - and social media in particular - to excel in their careers and balance their professional and family lives. Accordingly, this paper begins with an examination of the current research findings on social women's new models of work, levels of engagement, and transformational leadership styles. Women share content in multiple ways, and working online has been a financial windfall for many, including stay-at-home moms and homemakers. More women are doing what comes 'naturally', taking advantage of their so-called natural strengths, such as listening', sharing, building relationships, and creating a culture of collaboration.
\end{abstract}

Keywords: Gender, Technology, Women entrepreneurs, 'Feminine' skills, Leadership qualities, Social media

\section{Background}

Introduction: integrating the gender dimension

'Supporting women entrepreneurs is essential to stimulate growth since the entrepreneurial potential of women has not yet been fully exploited' (European Commission Vice-President Antonio Tajani, Commissioner for Industry and Entrepreneurship 2010). Europe needs more entrepreneurs, and actions are being taken to overcome obstacles and change mindsets by integrating the gender dimension/perspective into the equation, especially in view of the European Commission (2012a) recent figures (last update 02 February

(c) 2013 Kamberidou; licensee Springer. This is an Open Access article distributed under the terms of the Creative Commons Attribution License (http://creativecommons.org/licenses/by/2.0), which permits unrestricted use, distribution, and reproduction in any medium, provided the original work is properly cited. 
2012) according to which women entrepreneurs in Europe make up only 30\% of all entrepreneurs, an alarming decrease from 39.4\% in 2010! The European Commission's aim is to promote successful entrepreneurship and improve the business environment for small and medium-sized enterprises (SMEs) so that they can realize their full potential in today's global economy. Key drivers for economic growth, innovation, employment, and social integration are the 23 million SMEs in the EU today which represent $99 \%$ of businesses (European Commission 2012a). So integrating a gender perspective is not a matter of adding one more variable to the equation of social justice but an issue of integrating diversity into the system, as opposed to wasting it.

Integrating a gender perspective means eliminating the wastage of talent - utilizing all human resources, the entire talent pool - and as a result, boosting innovation which is a prerequisite for economic growth and sustainable development. The results of surveys conducted by the National Foundation of Women Business Owners show that the women-owned firms that are competing in the global market stimulate growth and are focused on business expansion. Women entrepreneurs have a significant impact on the economy not only in their ability to create jobs for themselves, but also in creating jobs for others. Research also shows that women entrepreneurs are highly educated, use more high technology systems than their male counterparts, and are an economic force to be reckoned with for sustainable economic recovery (Karacostas 2012; Sisson 2010). Additionally, women-owned businesses are more likely to have positive revenues since women entrepreneurs have a tendency to minimize risk so that their business and personal lives work in harmony (Kepler and Shane 2007).

Accordingly, this paper examines how women are using technology, digital tools to work independently, to market their brands or ideas, to monitor results instead of hours, and in particular to balance their personal/career lives. Indeed, entrepreneurship provides flexible working conditions not only for the women but for men as well, as confirmed in the recent European conference in Athens 'More Technologies? More Women entrepreneurs!' examined in the second part of this paper. A great number of women entrepreneurs have been relying on this flexibility to achieve the so-valued career-family balance.

A number of studies - examined in the first part of this paper - argue that women enjoy a slight edge over their male counterparts when it comes to teamwork, group communication skills, and social media. Researchers argue that women are better 'listeners' and that the collective intelligence of a group rises when the group includes women (Akalp 2010 (and in Babson college, http://blog.babson.edu/womensleadership/ 2010/05/03/three-women-entrepreneurs\%E2\%80\%99-perspectives-on-social-media);

Karacostas 2012; Kamberidou and Fabry 2011; Kamberidu and Labovas 2012; Cowley 2011; SheSpeaks Inc. 2011; Woolley and Malone 2011). Studies also show that femaleled ICT businesses and women-owned firms have been successfully competing in the global market (Fabry 2011)).

This does not mean that women are inherently more talented and better skilled than men. It does, however, indicate that gender diversity is essential to achieve better results. Namely, integrating the gender dimension means utilizing the entire talent pool men and women - so as to provide a competitive advantage. We need to work together to achieve economic growth and sustainable development. The main goal of integrating a gender perspective is that of gender equity/social equality for both women and men. 
Needless to say, gender issues do not only concern women! Men have a gender as well. Men also confront social inequalities and discrimination. For example, male migrant groups or ethnic minority entrepreneurs, another important pool of entrepreneurs in Europe, encounter exclusionary practices and obstacles: social discrimination, language barriers, limited access to funding, and support services as well as inadequate business, management, and marketing skills (Kamberidou and Fabry 2011).

Gender integration refers to the process of assessing and reassessing the implications for both women and men of any program and action plan at all levels: social, economic, and political. It requires gender-specific interventions, policies, and practices that may target exclusively women or interventions that target men exclusively or even men and women together. In fact, the goal of integrating the gender dimension into the equation is to transform exclusionary or unequal social and institutional structures into equal and just ones for both women and men. For example, an intervention that targets both women and men is Get Online Week 2013, a panEuropean awareness campaign empowering people to use technology and the internet - which ties in with the GrandCoalition for Digital Jobs officially launched at a conference in Brussels in early March 2013 - as over 20\% Europeans of both genders are young, unemployed, and mostly unaware that by 2015 , up to 900,000 vacancies for ICT-related jobs may remain open if jobseekers (men and women) do not acquire the right digital skills (European Commission 2013).

Integrating the gender perspective entails ensuring a gender balance, increasing the talent pool, and enabling everyone to realize their full potential. With regard to women, integrating a gender perspective means eliminating gender devaluation, namely, the subtle processes by which women's contributions are minimized, undervalued, or devalued (Kamberidou and Fabry 2012, Kelan 2010). It is a social, cultural, and technical process which requires shifts not only in organizational practices, attitudes, or ways of thinking, but also in resource allocations, goals, and structures along with monitoring processes. One needed point out here that many studies confirmed is that businesses and companies that utilize or take advantage of their female talent pool have an important competitive advantage and greater success rates. Companies with the most gender diverse management teams have average better results with regard to profits and sustainability (CEW 2009; Kamberidou and Fabry 2012).

\section{New models of work: Are female and male entrepreneurs really that different?}

'We are in a new era, that of a new technological revolution in which women can play a key role. The life cycle of such a revolution has a 40-60 year duration, and

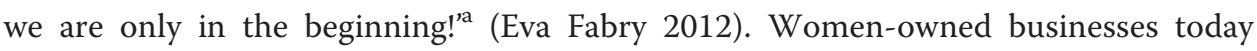
are on the rise, thanks to the Internet and social media in particular. Social women (SheSpeaks Inc. 2011) share content in multiple ways, and working online has been a financial windfall for many, especially stay-at-home moms and homemakers. Social networking is allowing women to inexpensively reach many target groups. What could be better for marketing a business? The bottom line is that social women are doing what most women do 'naturally', namely creating relationships, community, connections, and support. Is not that what social networking is all about? 
More and more people today are using technology, digital tools to work independently, to market their brands or ideas, to monitor results instead of hours, and in particular to balance their personal/career lives, which the in traditional model, namely, the long-hours tied down to a desk model does not permit (Kamberidou and Fabry 2012; IAWEO 2012). Technology as an enabler means flexible working conditions for both women and men. Digitally mobile lifestyles and virtual workplaces refer to new models of work, flexiprograms, and schedules, which are usually perceived as a benefit for women with children and associated with low commitment. This is untrue! Firstly, the demand for greater flexibility is not only about motherhood. Not only women want more flexibility in relation to work today. For example teleworking - working at home using a computer and phone is most common among highly skilled senior-ranking men (Cox and Maitland 2009).

New models of work are emerging due to globalization, changing demographics, and social attitudes. For example, parenthood is a role that men are increasingly sharing, and not only that! Men are also seeking the so-valued family-career balance. Additionally, the concept of retirement is dying as older people are now working beyond retirement age, and young people are taking time off to travel, study, work for non-profit organizations, do volunteer work, etc. In other words, careers are no longer linear and unbroken (Kamberidou and Fabry 2012). Needless to say, digital tools are also giving women the chance to build a business from home and create unique work schedules, especially working moms. So are male and female entrepreneurs really that different?

Then again, in response to this question, in a study conducted for the Small Business Administration (SBA), Erin Kepler and Scott Shane (Kepler and Shane 2007) argue that they are, as far as priorities are concerned. Kepler and Shane (2007) observe that women entrepreneurs in the US are more likely to prioritize and minimize risk so that their business and personal lives work in harmony, whereas male entrepreneurs primarily focus on starting a business to make money and have higher business expectations. No doubt, the digital age has made it more feasible for risk-averse aspiring entrepreneurs of both genders to start a business. A wealth of low-risk opportunities and ventures like e-commerce, blogging, web-based services, cloud-based tools, and virtual workforces further lower the entry cost. The SBA study shows that the tendency to minimize risk can lead to higher success rates for female entrepreneurs, that is, woman-owned businesses are more likely to have positive revenues. However, Kepler and Shane (2007) argue that this could also be described as risk-phobia which could mean that women are more likely to place limits on the size of their business and are less likely pursue outside funding from investors to stimulate growth. Could this mean that women require male mentors and collaborations with men so as to overcome such obstacles?

\section{'What makes a team smarter? More women!'}

Anita Woolley and Thomas Malone (Woolley and Malone 2011), in a study published in the Harvard Business Review, argued that the more women on board the better the results. The study finds that the collective intelligence of a group rises when the group includes more women, even though there is little correlation between a group's collective intelligence and the IQs of its individual subjects. According to their findings, women excel in communication skills and are better listeners than men.

Specifically, female and male subjects aged 18 to 60 were given standard intelligence tests and were randomly assigned to teams. Each team was asked to solve one complex 
problem - and to complete several tasks, including decision making, brainstorming, and visual puzzles - and given intelligence scores based on their performance. The teams that had members with higher IQs did not earn much higher scores, as was expected, whereas those that had more women on board did. The female factor seems to play a major role here or rather, gender diversity is essential.

The study also finds that women tend to be stronger at drawing people into conversation and, in addition, are better listeners, a great advantage for the entrepreneur who can better attune herself to customer needs and build more effective employee teams and partnerships. In fact, Wooley and Malone (2011) pointed out that many women entrepreneurs described building their business as building a team. They also argue that women entrepreneurs share criticism constructively, have open minds, and are not autocratic.

Another study conducted by a research team in the UK, after examining how men and women communicate, said men speak more words than women in a day; but in social situations, they have a weaker command of language, use the same words repeatedly, and pay unconvincing compliments (Cowley 2011). Researchers found that men and women used similar language when conversation centered on issues such as current affairs or politics; however, they differed widely when it came to social talk and chit-chat. This study seems to dispel the myth or the gender stereotype that women are chatterboxes: 'It is men who are more likely to talk for the sake of talking when engaged in social chit-chat by recycling their words with ritualistic and redundant language that doesn't contain new information,' argues Manchester University researcher Geoffrey Beattie (Cowley 2011).

More analytically, for over a one-week period, researcher teams carried recording devices and transcribed 50 conversations, which were split between men and women in serious and social conversations. Subsequently, each conversation was given to five volunteers who read five different versions with every fifth word erased. The volunteers were asked to guess the missing word. According to the researchers, in social situations men used a few simple words, and when it came to paying compliments, the limited variety of their vocabulary became even more obvious. The study showed that compliments from women had more detail, making them less predictable and more genuine, while men were $90 \%$ predictable and frequently used words such as 'really' and 'nice' (Cowley 2011).

By the year 2018 women's so-called social skills will be in great demand. The work world will be more fluid and virtual, and the demand for female management skills will rise dramatically! The UK Chartered Management Institute (CMI) predicts that by the year 2018, women will be moving rapidly up the chain of command because their emotional intelligence skills will be indispensable and valued. This trend will also accelerate due to the alarming talent shortage, as argued by Shipman and Kay (2009) in an article citing the CMI projections entitled 'Women will rule business' (read more in http://www.time.com/time/specials/packages/article/0,28804,1898024_1898023_ 1898078,00.html \#ixzz1xBlC94PA).

Shipman and Kay (2009) argued that women are 'consensus builders, conciliators and collaborators, and they employ what is called a transformational leadership style-heavily engaged, motivational, extremely well suited for the emerging, less hierarchical workplace.' At this point, one must also call attention to the alarming prediction that if there is no drastic change in the female employment rate, demographic developments in Europe indicate that by the year 2036, there will be a drop of 24 million in the active 
workforce! Moreover, to reiterate with regard to the European ICT sector, the Commission estimates that by the year 2015 there will be up to 900,000 vacancies if jobseekers do not acquire the right digital skills (European Commission 2013).

In today's digital economy, the so-called 'feminine' skills and leadership qualities (e.g., listening, sharing, and team building) that promote and reproduce a culture of collaboration - whether the result of socialization, social conditioning, or biology - are significant now, more than ever!

\section{Social women listen and share}

The top self-described traits of the 'social woman' (SheSpeaks Inc. 2011) is that she listens and shares, according to the results of an online survey with 3,963 women in the USA, conducted 13 to 15 September 2011. The survey shows that the social woman wants to share and listen and not just use the internet or social media as a megaphone to get her voice heard. More analytically, the SheSpeaks Inc. (2011) findings show the following:

- Eighty-two percent 'listen carefully to the opinions of others', rather than debating or trying to convince others of their own views.

- Only $40 \%$ enjoy trying to change other people's minds.

- Eighty-six percent are motivated to share when they find information that would be interesting to others.

- Women listen to their friends, gather information, and then share it with other friends: online news being the top source of information (57\%), followed by TV (50\%), social media posts (49\%), and email (48\%).

- Their friends are the most influential people in their lives (83\%), more than their spouse/partner (68\%), professional experts (46\%), or parents (44\%).

- Over half of the respondents (57\%) agree that young people spend too much time connecting with others online or texting, and that this is harmful for their future relationships.

Although social media is the talk of digital and marketing professionals (Storck 2011; Marien and Van Audenhove 2010; Kaplan and Haenlein 2010), women of all demographic groups prefer the personal touch and sharing face-to-face with each other: e.g., $89 \%$ say they prefer personal contact, compared to $67 \%$ who like to share via social networking. Even though $84 \%$ say that 'social media helps me feel more connected to others', the vast majority (93\%) across all age groups agree that technology helps them connect with others, adding, however, that face-to-face relationships are more satisfying (SheSpeaks Inc. 2011).

The statistics of the SheSpeaks study show that women have high levels of engagement and share content in multiple ways, e.g., Facebook and smartphones are the fastest growing sharing mechanisms. Moms interact twice as much online with more people than non-moms (homemakers). Homemakers - women who work at home - are active bloggers and engage online more consistently than moms. Almost two thirds (63\%) of the homemakers say that 'Working at home (either as a homemaker or professional who works at home) makes me feel isolated sometimes', and (68\%) started a blog in order to 
connect with others. SheSpeaks Inc. (2011) also shows that sharing for moms - who interact twice as much online than non-moms - is more about inspiring change, making a difference in the world, feeling good about themselves, and wanting to make the world a better place for their children. For instance,

- Sixty percent of moms share because they want to inspire change (50\% for homemakers/women with no children), and they believe they can make a difference by sharing ( $63 \%$ moms vs. $52 \%$ homemakers).

- Moms (51\%) are more likely to comment on issues important to the local community' (51\% moms vs. 38\% homemakers).

- Unlike homemakers, moms over-index in sociability and say they 'seem to know everyone' (42\% moms vs. 28\% homemakers).

- Prefer to share by posting on social networking ( $73 \%$ moms vs. $57 \%$ homemakers).

\section{Europe needs more entrepreneurs}

Europe needs more entrepreneurs and actions are being taken to overcome obstacles and change mindsets, especially in view of the fact that women entrepreneurs in Europe today make up only $30 \%$ of all entrepreneurs. Examples of these mindsets, namely social attitudes and stereotypes, are clearly displayed in a recent study conducted at Tallinn University of Technology (TUT) in Estonia. TUT, being the forerunners in ICT fields and in initiating technologies such as Skype, decided to investigate possible scenarios on how their female students see their input in entrepreneurship. Online questionnaires were sent out to female students in order to gain a more coherent understanding of gender and how it affects career choices and what could be done to improve the underrepresentation of girls/women in ICT. According to the results of the survey, women do not want to start their own information and technology (IT) company, and the reasons given were (1) fear of new things, (2) unwillingness or lack of courage to be a leader, (3) fear of the responsibility, (4) work-life balance, (5) competing with men, and (6) professional competence (WiTEC 2012).

To eliminate such obstacles or gender stereotypes, the EC has been systematically promoting, supporting, and encouraging female entrepreneurship. For example, the recent conference in Athens 'More Technologies? More Women entrepreneurs!' is presented in the next section of this paper. Additionally, the creation of the European Network of Female Entrepreneurship Ambassadors in 2009 (European Commission 2012a) and the European Network of Mentors for Women Entrepreneurs inaugurated in Warsaw during a Polish Presidency event on 15 November 2011.

The European Network of Mentors for Women Entrepreneurs is one of the actions proposed in the 2011 Small Business Act Review to promote female entrepreneurship in Europe in order to stimulate growth (European Commission 2012a). To date, 17 countries have joined the European Network of Mentors for Women Entrepreneurs: Belgium, Hungary, Greece, Cyprus, Ireland, Italy, the Netherlands, Romania, Slovakia, Slovenia, Spain, UK, Albania, Turkey, the former Yugoslav Republic of Macedonia, Montenegro, and Republic of Serbia.

The European Network of Mentors for Women Entrepreneurs is extremely active. For example, only the Greek branch has established 104 business mentors and mentees 
(Stavropoulou and Protopapa 2012). Specifically, the Greek branch ('business mentors') to date has 103 members: 51 mentors, even though they were only required to recruit 26 mentors, and 52 female mentees. In other words one mentor per mentee. The Greek branch has already completed three training sessions for mentors, two in Athens and one in Thessaloniki in May 2012; held a webinar for the mentees in June 2012; and matched the mentoring couples and introduced them to each other at the kick off session in July 2012. Additionally, to ensure that these relationships run smoothly for the entire duration, webinar sessions are being held for mentors every 3 months, the first began last September 2012 and the last one will be held on August 2013.

With regard to the Ambassadors Network - the European Network of Female Entrepreneurship Ambassadors - it was launched in Stockholm during the Swedish Presidency in 2009. The second phase was inaugurated in 2010 during the networking event that was co-organized by the European Commission and the Belgian Presidency of the European Council, at which European Commission Vice-President Antonio Tajani, Commissioner for Industry and Entrepreneurship said: 'Europe must build on its small businesses. Supporting women entrepreneurs is essential to stimulate growth since the entrepreneurial potential of women has not yet been fully exploited. Our initiative will play an important role in encouraging women to take the plunge and launching their own businesses which will be good for them and great for a sustainable economic recovery.'

Today, the Ambassadors Network - which focuses on the role that women can play in creating jobs and promoting competitiveness - is made up of around 270 entrepreneurs coming from 22 European countries (European Commission 2012b). By testifying to their experience in schools, at universities, and in the media, these ambassadors serve as role models and mentors inspiring women to have an independent career. Since the establishment of the European Network of Female Entrepreneurship Ambassadors, many initiatives and programs have been implemented, such as (1) the setting up of a micro-credit, mentoring, coaching, and grant programs targeting female entrepreneurs in Spain; (2) the establishment of a specific mentoring programs in Latvia; (3) organizing women entrepreneurs' days in Romania; (4) encouraging entrepreneurship among women graduates in the UK 'Women's Enterprise Ambassadors' and a 'Flying Start' program; and (5) the previously mentioned European Network of Mentors for Women Entrepreneurs inaugurated in Poland on 15 November 2011 (European Commission 2012b).

\section{'More technologies? More women entrepreneurs!'}

The promotion and support of female entrepreneurship and how information and communication technologies (ICTs) can facilitate, promote, and support it were discussed at the European conference 'More Technologies? More Women entrepreneurs!' held in Athens on November 6, 2012 at which 12 European projects (http://gender-it.eu/? page_id=1395\&lang=el) were presented. Projects that can help the women of Europe - regardless of age, race, or ethnic background - pursue entrepreneurship (Kamberidou 2012).

The European conference, workshops, and project show case (12 projects) highlighted and showed women - and men - the advantages and opportunities that ICTs can offer them for the development of their business initiatives and activities. The event was the 
final conference of the ladybizIT project (www.gender-it.eu) and was organized by Militos Emerging Technologies and Services and its partners: the European Centre for Women and Technology (ECWT), the Hellenic Professionals Informatics Society, ITEC Training \& IT Services, and OLN Learning.

Specifically, ladybizIT built up a dialogue through a set of interlinked and complementary dissemination actions that are culminated into the European conference and show case of the 12 European best practice projects, under the umbrella of the EU Lifelong Learning Programme 2007 to 2013. These successful projects focus on women entrepreneurship, how ICT facilitates and fosters it, transfers knowledge with a strong innovative character, and upgrades the level and quality of vocational education and training (VET) in countries around Europe. The presentation of such best practices could set the grounds for future innovative practices that will be built on the previous results with a potential to be replicated in different VET systems.

Despite the severe difficulties caused by the wave of strikes in Athens, including the strike of all the mass means of transportation, almost 300 participants attended the conference physically and 195 participated through live web streaming. In her report to the European Economic and Social Committee, Madi Sharma, keynote speaker of the conference and Member of the Employers Group points out that the conference on female entrepreneurship was extremely valuable in terms of information provided, plus networks and knowledge. Additionally she observes: 'For me this was an especially valuable event because of the high attendance of participants, men and women, despite the strike in Greece that day and because this was a European funded project. Despite the topic being female entrepreneurship (DG Enterprise) and women in IT (DG CONNECT) the fund for the project was from DG Education and Culture as part of the Life Long Learning promotion. This demonstrates the cohesive and coordinated approach that needs to continue to take place at European level if we are to deliver results on growth, jobs, and entrepreneurship.'

Speaking at the opening of the European conference the Head of the Representation of the European Commission in Greece, Dr. Panos Carvounis stressed that gender equality is a fundamental right and a vital source for future economic development and competitiveness and that female entrepreneurship constitutes a dynamic and essential source for development. He pointed out that the new EU program Equality pays off! which was launched by Vice-President Viviane Reding, in August 2012, will also help countries achieve a gender balance, adding that a gender balance is also being promoted with regard to women's participation on the board of directors.

Soon after the conference in Athens on November 14, 2012, the European Commission approved a Directive on Gender Quotas on the Boards of Directors for companies listed on the stock-exchange.

'We do not have a culture of collaboration in Greece, consequently we do not have a culture of entrepreneurship' said Dr. Theodore Skylakakis, member of the European Parliament. He argued that there is a wastage of talent of a significant part of society, that of women [...] modern societies have $50 \%$ of their talent in women, but use only a small percentage of it.' He also pointed out that although business success rates are higher when we have more women on board, there are still extreme inequalities observed throughout Europe. 
'We are in a new era, that of a new technological revolution in which women can play a key role. The life cycle of such a revolution has a 40-60 year duration, and we are only in the beginning!' said Eva Fabry, the Director of the European Centre for Women and Technology (ECWT) and co-chair of the Women's International Research Engineering Summit - WIRES 2013.

'Entrepreneurship is all weather, meaning that it does not have a gender, an age, a race or an ethnic background' argued Olga Stavropoulou, Managing Director of Militos Emerging Technologies \& Services as well as a the coordinator of the Greek part of the European Network of Mentors for Women Entrepreneurs. It is always current and contemporary, especially during periods of crisis where innovative and successful entrepreneurial activities surface and appear on the scene, adding 'We need to get rid of the stereotypes, because they are out of fashion'. Olga Stavropoulou also described how she began her business and how as a working mom who had just given birth to her first child and that new technologies are helping her expand her it.

'We cannot have change unless we have men in the room', argued the next speaker Madi Sharma, an entrepreneur running the Madi Group, a group of private sector and not for profit companies with a philosophy to create innovative ideas tailored to local action which can achieve global impacts beneficial to society. Madi Sharma told participants that she began her business in her kitchen as a single mother and is today working in India and across Europe with diverse businesses and governments. 'We should not be afraid of the economic crisis [...] I have a global business but I do not have an office and my biggest client is based in the US. I have used technology to grow my companies [...] My skills are me, what I believe in what I know I can do [...]. Female entrepreneurship is not a gender issue but an economic issue and that is why it needs supporting!' Madi Sharma argued.

Madi Sharma also pointed out that women are undercapitalized because they take reduced risks; however, they still fail less than men. Women also care about communities and do social-corporate responsibility which is not recognized. 'So women are not ideal targets to be backed by policy makers that do not recognize us. Policy makers are male and sadly so are the bankers, and this is why we need change. We need a representative who understands female entrepreneurship. We need a Business Ministry for Women!' she concluded.

'There is no Victory without a Team! You begin by dreaming, the dream becomes a business and the planet is my neighbourhood' said Anastasia Manou, member of the European Network of Mentors for Women Entrepreneurs, who began her business activities in 2005 -with documentary productions and film distribution - and today is a shareholder and CEO of White Fox S.A.

'New technologies are providing new opportunities for women entrepreneurs' argued the next speaker George Flessas, President and CEO of CIVITAS S.A., the largest strategy communications and public affairs company in Greece today. George Flessa presented examples and case studies of successful female entrepreneurship, such as NETROBE (http://www.netrobe.com/) which has reached the global market due to the social media and new technologies. Mr. Flessas pointed out that 'social media has been developing with rapid speed, the world has changed, the way we shop has changed and the way we communicate has changed. There is a new culture that is leading to a new consumer-citizen, who is thirsty for something new and tires of it quickly.' 


\section{Demystifying the world of new technologies: a culture of collaboration}

There was a consensus on the issue of obstacles confronted by women entrepreneurs such as limited use or access to ICT tools. On the other hand, conference participants agreed that the number of female-run business have been increasing due to the social media. Many speakers, and especially women entrepreneurs, demystified the world of new technologies through the lens of their own experiences, focusing in particular on how the social media supported the development and success of their businesses.

More analytically, the next section presents the results of the European conference 'More Technologies? More Women Entrepreneurs' (6 November 2012), as wells as those of the exploitation round table discussion that followed (15 November 2013). Specifically, after the conference, the European Centre for Women and Technology (ECWT) and the Hellenic Professionals Informatics Society (HePIS) co-organized the exploitation round table in Athens last 15 November 2013, in the framework of the European project ladybizIT: Women Entrepreneurship on the Verge of ICT.

\section{Results and discussion}

Tips from women entrepreneurs:

- Stop being scared of technologies and get to know them better!

- Invest on a good internet connection.

- Take advantage of the available European projects with ready-to-use online educational and training material at no cost.

- Be practical and set realistic goals.

- Seek synergies and work on common ideas.

- Find online groups, fora, and social networking sites that are created by women and for women since these usually offer support, connections, information, marketing opportunities, and more.

- Present successful women entrepreneurs as role models and learn from their experience (storytelling).

- Connect with a diverse range of people from all around the world, people you may never have discovered without the social media.

- Learn to use the analytical tools that help you determine the impact your social media networking is having on your business.

- Social media compliments marketing efforts; for example, Twitter is great for 'trial and error' in the social media world. Whatever you put up there only lasts about 15 min, so you can test things out without worrying that it will remain in cyberspace to haunt you.

- Practice makes perfect: navigate, explore, tweet new ideas, products, etc.

- Stay specific: target customers and focus on information that builds customer trust. This means that your social media is interested in your customer and not just on making a sales pitch.

- Whatever you post on social media should add value to the reader's experience and encourage them to come back to you for more. Once you or your business has been 'recognized' in the social media, they will be more apt to respond to traditional outreaches through email. 
- Refrain from over posting; avoid being one of those who exhaust social media friends with multiple postings.

- Create a circular flow of communication through that ultimately and always brings your clients back to your website.

- Decide on your framework or brand in the social media outlets: some social media are more relevant to certain aspects of your business development than others.

- Use social media as an integrated part of your business marketing approach.

\section{The family/career balance: ladybizlT exploitation round table}

During the exploitation round table discussion in Athens participants focused on social stereotypes, attitudes, and gender barriers. The discussion began with observations such as women tend to work in groups, they have a collaborative attitude and team spirit; however, social stereotyping and socialization have created strong obstacles with regard to their initiatives or readiness to embark on an entrepreneurial career.

Specifically, all participants repeatedly highlighted the difficulties in balancing family and professional/career life, and especially in traditional societies and cultures, such as Greece, where the sandwich generation or the sandwich woman is still observed. This refers to women's multi-tasking which includes taking care of children and parents or parent-in-laws simultaneously; being pulled in two directions, work and family responsibilities; and facing emotional difficulties as well as problems in allocating time and money. Subsequently, participants observed that taking into account the cultural perspective is vital. One round table participant, who is in charge of a mentoring program, said her female mentees were unreliable and not ready to be mentored since they had other priorities (family obligations), so they tended to cancel their appointments, were too busy to participate, etc. All participants agreed that when men decide to embark on a professional career, open their own business, and become entrepreneurs, they have the full support of institutions, the family, and the social environment, as opposed to women.

On the other hand, they argued that cultural barriers will drop or rather begin to change due to new technologies, social media, access to knowledge and information and so forth. This brought about a discussion on what is productivity, what is knowledge, what is information, especially with regard to speed and interpretation and how do we measure them? The majority of the participants repeatedly observed that we need training, and we need to be re-educated to sort out the abundance of information in a society of services and not one of a production of knowledge, a meaning which changes according to social space and time. Many observed that we need to also explore the ways in which the connected generation will be collaborating and working, taking into account the emerging trends and how to turn them into a competitive advantage; e.g., business today is different from that of 20 to 30 years ago due to new technologies; and, as a result, working cultures are changing. Indeed the social media, the digital culture, and, for many, a new and stimulating environment have become a significant part of our daily activities. Yet we have hardly begun to understand to what extent the new media has changed our daily lives, practices, habits, and culture. All agreed that we need to focus on identifying new opportunities and 
best practices by exploring if more technology really means more progress, efficiency, and knowledge.

Discussions also focused on the need for guidance and assistance in submitting proposals for projects, since women (and men) confront many barriers here, e.g., terminology and hostile language. The majority argued that EU calls are primarily directed to those with experience and know-how; it is difficult to decipher information for calls, making it impossible to participate; the EU uses difficult language and, consequently, only those with the know-how can apply; calls are usually directed to those with experience in preparing project proposals, etc. The next section presents the proposals/recommendations that came out of the ladybizIT exploitation round table.

\section{Get them while they are young and disseminate mistakes}

Education: integrating the gender perspective

- Focus on changing stereotypes, get them while they are young, before they start formulating stereotypes, e.g., from kindergarten or primary school. How can this be accomplished? By incorporating the gender dimension into the public school systems

- Begin from bottom up and set up incubators such as education/training

- Educating the educators and training the trainers

- Classes, seminars, and workshops for parents

- The implementation of unschooling (a practical educational methodology) practiced in the USA, rather than the traditional school curriculum. Proponents of unschooling argue that this self-directed education makes a child more equipped to handle the real world.

\section{Entrepreneurship: disseminate mistakes}

- Record, register, or list all the mistakes that women entrepreneurs have made and are making (and not only women).

- Establish a gender-sensitive mentoring program for male mentees (with women mentors).

- We not only need more role models and women's testimonies/narratives/ storytelling, but we also need to actively promote, disseminate, and display these new role models and their stories in mainstream media, new media, etc.

- Accountability practices or penalties: women (and men) who participate in mentorship programs and are unreliable should be excluded/removed from the program and replaced by new mentees.

\section{Toolkit, mapping and more!}

- Prepare a toolkit for new female entrepreneurs.

- Establish monthly or regular workshops and round tables and/or discussion groups to check the implementation and progress of the toolkit: Advise and provide further assistance with regard to problems confronted. 
- Target and fill gaps that are in the market today, e.g., incentives for women such as tax exemptions, funding, and insurance reductions.

- Set up a group of experts to discuss how to evaluate the course of women entrepreneurs: progress, efficiency, productivity, and best practices.

- Establish a common evaluation system that will follow, on a regular basis, the career paths of women entrepreneurs with accountability measures. We cannot only provide funding, tax exceptions, etc. and then forget about them. For example, we know that women's businesses that have been financially supported and have not been evaluated, reviewed, or rated. Why do they usually close after 3 years, and what problems did they confront? This is why training and systematic reviewing during this professional period are required. In other words, funding/ financing must be accompanied by other actions and policies.

- Consequently, this requires a mapping of women's entrepreneurship. Such a mapping is needed in Greece for men's entrepreneurship as well.

- Providing consulting services and/or a volunteer support system to keep business activity competitive. A volunteer support system for both women and men entrepreneurs to assist them in surpassing barriers - such as bureaucracy systems are needed to enable them to accomplish their vision.

- The establishment of a multicultural group of experts from diverse fields to discuss questions/issues, such as those raised at the round table on what is knowledge, what is information, what is efficiency, what is productivity, and how do we measure them? This group of experts could promote seminars, workshops, and discussion groups for women to learn how to distinguish knowledge from information and as one round table participant pointed out 'in order to act you need to know, but in order to know you need to discover how to know. This we cannot do alone.'

- Set up a task force (experts team) to provide guidance with regard to access to information, specifically, to assist women in finding projects, identifying calls, preparing proposals, etc., since women (and men) confront many barriers here.

\section{Conclusions}

Indeed, entrepreneurship has a tremendous potential in empowering women. It is a driving force for economic development, job creation, personal development, and selfempowerment. Yet this potential remains largely untapped. Women entrepreneurship is indispensible for long-term economic growth in today's high-tech world. How ICTs can facilitate, promote and support female entrepreneurship is clearly illustrated in the results of this study, and especially in those of the European conference 'More technologies? More women entrepreneurs!' The women of the twenty-first century are no longer a traditional resource confined to the gendered sphere of the household, but an innovative and knowledgeable part of the population that contributes to economic growth. They are challenging and transforming work cultures. For example, many studies have shown that women entrepreneurs focus on creating a collaborative work environment are comfortable sharing information and sharing power, possess a democratic managerial approach, and prefer teamwork. Certainly, in many parts of the world, in developing and developed countries, ground realities are different. In fact, one need which is reiterated here that the goal of integrating the gender dimension into the equation is to transform exclusionary or unequal social and institutional structures into equal and just 
ones for both women and men. Exploiting the full potential of the individual, of all human resources, regardless of gender, race, religion, etc., is one of the greatest challenges and is vital for sustainable development. Consequently, it is vital to encourage long-term female entrepreneurial involvement in order to foster socioeconomic growth.

\section{Methods}

How women entrepreneurs are challenging and transforming traditional understandings of professional success: work, learning, and career? What type of knowledge do they value while growing a business, and how do they develop this knowledge? Are women's choices a result of changing dynamics or are they shaping the changing socio-cultural dynamics and discourses? Do women satisfy their personal needs when they run their own business? What is being done to support female entrepreneurship and in particular promote the ways in which ICTs can encourage and facilitate it? Is today's business climate more inviting to women entrepreneurs? Are women equipped to thrive in this digital age?

To address these questions, as well as the numerous and diverse benefits of female entrepreneurship, this paper provides a literature review of the prominent characteristics of women's entrepreneurship, which is approached first through an analysis of the existing bibliography, and includes research papers, journal articles, and case studies, and next through the presentation and analysis of data drawn mainly from surveys exploring personal characteristics and motivation (Akalp 2012; European Commission 2012a, b; Karacostas 2012; Kamberidu and Fabry 2012; Kamberidu and Labovas 2012; Woolley and Malone 2011; SheSpeaks Inc. 2011; IAWEO 2012; Sisson 2010; Shipman and Kay 2009; Cox and Maitland 2009; Kepler and Shane 2007).

A growing body of research of the twenty-first century explores the characteristics, motives, leadership styles, management skills, and strategies of the female entrepreneur, documenting case studies and strategies for success. (Akalp 2012, et al.) A number of researchers argue that further studies are required, but all agree that innovation or the drive for innovation is the first criteria for successful entrepreneurship, especially in developed countries.

Accordingly, this paper begins with an examination of the current research findings and surveys on social women's new models of work, levels of engagement, and transformational leadership styles. It compares these with the results of the recent European conference 'More technologies? More women entrepreneurs!' held in Athens last November 6, 2012 as well as those of the Exploitation Roundtable on Female Entrepreneurial Activity held in Athens last November 15, 2012 where participants focused on social stereotypes, gender barriers, and attitudes. As a result, this paper presents Tips from successful women entrepreneurs - who participated in the conference and round table discussion and who told how they had been using new technologies and the social media in particular - to excel in their careers and balance their professional and family/private lives.

\section{Endnote}

${ }^{a}$ The Director of the European Center for Women and Technology (ECWT) speaking at the European conference in Athens, Greece 'More Technologies? More Women Entrepreneurs!' (ladybizIT) in November 6, 2012. 


\section{Competing interest}

The author declares that she has no competing interest.

\section{Acknowledgement}

"Creativity and Entrepreneurship" by the artist Areti Kamperidis.

Received: 16 March 2013 Accepted: 7 May 2013

Published: 25 May 2013

\section{References}

Akalp, N. (2010). Three women entrepreneurs' perspectives on social media. Women entrepreneurs grow global. http://womenentrepreneursgrowglobal.org/2010/05/05/three-women-entrepreneurs-perspectives-on-global-socialmedia/ Accessed 3 June 2012.

Cowley, M. (2011). Women have gift of the gab over chatterbox men. Reuters Life! London, Friday Feb. 18, 2011 4:48am EST. http://www.reuters.com/article/2011/02/18/us-communication-gender-differences-idUSTRE71H1SE20110218. Accessed 17 May 2013.

Cox-Wittenberg, A, \& Maitland, A. (2009). Why women mean business. Chichester: Wiley.

CEW. (2009). The business case for women as leaders: one woman is not enough. Chief executive women (CEW), women leader enabling women leaders, Feb. 2009. http://wilg.org.au/wordpress/wp-content/uploads/2011/11/ TheBusinessCaseforWomenasLeaders.pdf. Accessed 12 November 2012.

European Commission. (2013). Get Online Week 2013 (GOW2013). Digital agenda for Europe. European Commission http://ec.europa.eu/digital-agenda/en/news/get-online-week-2013-gow2013. Accessed 16 March 2013.

European Commission. (2012a). Small and medium-sized enterprises (SMEs). Encouraging women entrepreneurs. Enterprise and Industry. http://ec.europa.eu/enterprise/policies/sme/promoting-entrepreneurship/women/index_en.htm. Last update: 02/02/2012. Accessed 7 June 2012.

European Commission. (2012b). Small and medium-sized enterprises (SMEs) European Network of Mentors for Women Entrepreneurs - National contact points. European Commission Enterprise and Industry. http://ec.europa.eu/enterprise/ policies/sme/promoting-entrepreneurship/women/national_contacts_en.htm.

Fabry, E. (2011). Women for smart growth workshop. Brussels: Working paper for the Digital Agenda Assembly, 16-17 June 2011.

IAWEO. (2012). International Association of Women Entrepreneurs online, helping women create successful online businesses. IAWEO. http://www.iaweo.com/standing-out-on-social-media-40-women-entrepreneurs-share-theirsecrets/, February 12, 2012. Accessed 3 June 2012.

Kamberidou, I. (2012). Debrief. More technologies? More Women Entrepreneurs! http://gender-it.eu/wp-content/uploads/ 2012/11/ladybizIT-debrief-FINAL.pdf. Accessed 20 February 2013.

Kamberidou, I, \& Fabry, E. (2012). Redefining professional success and concepts of excellence: integrating a gender perspective. Reflections on women in entrepreneurship and ICT/A reader. Militos Emerging Technologies \& Services (pp. 10-27). www.gender-it.eu. Accessed 20 February 2013.

Kamberidou, I, \& Labovas, M. (2012). Social women share: technology as an enabler. Reflections on women in entrepreneurship and ICT/A reader. Militos Emerging Technologies \& Services (pp. 62-78). www.gender-it.eu. Accessed 20 February 2013.

Kaplan, AM, \& Haenlein, M. (2010). Users of the world, unite! The challenges and opportunities of Social Media. Business Horizons, 53(1), 59-68.

Karacostas, S. (2012). Women entrepreneurs \& social marketing - a natural fit. Topic: small business marketing. StartupNation. http://www.startupnation.com/business-articles/9567/1/women-entrepreneurs-social-marketing.htm. Accessed 3 May 2012.

Kepler, E, \& Shane, S. (2007). Are male and female entrepreneurs really that different? SBA - Small business research summary, advocacy: the voice of small business in government no. 309, September 2007 (pp. 1-61). http://archive.sba. gov/advo/research/rs309tot.pdf. Accessed 3 May 2012.

Kelan, E. (2010). Performing gender at work. New York: Palgrave Macmillan.

Marien, I, \& Van Audenhove, L. (2010). Embedding e-inclusion initiatives in people's daily reality: the role of social networks in tackling the digital divide. The Clash of Cultures. 20 Sept. 2010 (pdf in SMIT-Studies Media Information Telecommunication). http://smit.vub.ac.be/publication/627/Embedding_e-inclusion_initiatives_in_people_s_daily_ reality_The_role_of_social_networks_in_tackling_the_digital_divide_. Accessed 3 May 2012.

SheSpeaks Inc. (2011). Why She Shares, SheSpeaks Inc. December 12, 2011. http://www.shespeaks.com/pages/img/ insightreports/SheSpeaks\%20SheShares\%20Study_04302012140512.pdf. Accessed 20 February 2013.

Shipman, C, \& Katty, K. (2009). The new work order: women will rule business. Time Special. http:/www.time.com/time/ specials/packages/article/0,28804,1898024_1898023_1898078,00.html (Thursday, May 14, 2009). Accessed 20 February 2013.

Sisson, N. (2010). Top 20 women for entrepreneurs to follow on Twitter. Forbes. http://www.forbes.com/sites/work-inprogress/2010/07/26/top-20-women-for-entrepreneurs-to-follow-on-twitter/print/. Accessed 3 March 2012.

Stavropoulou, O, \& Protopapa, S. (2012). Passing the torch: mentoring and learning in women entrepreneurship. Reflections on women in entrepreneurship and ICT/A reader (pp. 36-46). Militos Emerging Technologies \& Services. www. gender-it.eu. Accessed 20 February 2013.

Storck, M. (2011). The role of social media in political mobilisation: a case study of the January 2011 Egyptian uprising. M.A. Dissertation, University of St Andrews, Accessed 3 March 2012. http://www.culturaldiplomacy.org/ culturaldiplomacynews/content/articles/participantpapers/2012-02-bifef/The_Role_of_Social_Media_in_Political_ Mobilisation_-_Madeline_Storck.pdf. 
WiTEC. (2012). Mindset of knowledge workers: how to increase awareness of female Entrepreneurship in ICT sector. WiTEC the European Association for Women in Science, Engineering and Technology (SET), WITEC ESTONIA. WiTEC Newsletter 04/2012. http://www.witec-eu.net/. Accessed 5 May 2012.

Woolley, A, \& Malone, T. (2011). Defend your research: what makes a team smarter? More women. Harvard business review. http://hbr.org/2011/06/defend-your-research-what-makes-a-team-smarter-more-women/ar/1】. Accessed 20 February 2013.

doi:10.1186/2192-5372-2-6

Cite this article as: Kamberidou: Women entrepreneurs: 'we cannot have change unless we have men in the room'. Journal of Innovation and Entrepreneurship 2013 2:6.

Submit your manuscript to a SpringerOpen ${ }^{\circ}$ journal and benefit from:

- Convenient online submission

- Rigorous peer review

- Immediate publication on acceptance

- Open access: articles freely available online

- High visibility within the field

- Retaining the copyright to your article 